\title{
Work-Life Balance In Hospitality: Experiences From A Geneva-Based Hotel
}

\author{
Robert A. Lewis, Les Roches Gruyère, University of Applied Sciences, Switzerland
}

\begin{abstract}
This study, carried out on 30 employees in a Geneva-based hotel, argues that employee work-life balance issues are affected by human resource policy. Questionnaires, containing attitude scales and open-ended questions, revealed that employees remained in their jobs because of work-life programmes. Variables identified in this study which positively affected employee well-being included increased schedule flexibility and mutually beneficial relationships with line managers. Negative ones included long working hours, the sacrifice of private life, invasive working hours, decreased social and family life in addition to increased fatigue and stress. Study results also revealed that work-life balance issues perceived by employees can be mitigated through organisational support and the recognition of informal feedback.
\end{abstract}

Keywords: work-life balance, work-life balance in hotels, work-life balance in hospitality, work-life balance in Switzerland

\section{INTRODUCTION}

\section{Study objectives}

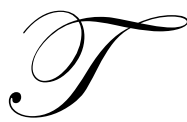

he objective of this study is twofold. First, it aims to bring to light advantages and disadvantages of work-life balance issues from the perspective of employees in a Geneva-based hotel. Second, this study provides results that can potentially be used to improve human resources policy in similar organisations. This study suggests that hotels can attract and retain high quality staff by measuring work-life balance implications for employees. Work-life balance, for the purpose of this paper, refers to the way people manage sets of issues linked to their work- versus non-work lives.

\section{LITERATURE REVIEW}

\section{Introduction}

This review attempts to critically evaluate the current literature on flexibility issues, work-life balance initiatives in Europe, in Switzerland and in the hospitality industry. It ends with a set of research questions.

\section{Flexibility issues}

Respondents in European Union (EU) studies suggest there is an increased desire from workers for more flexible working schedules, with a significant movement beginning in the 1980s (European Foundation 2003). These schedules include part-time work, compressed work weeks, term-time working, job sharing, teleworking and flexible retirement (by reducing hours in periods before retirement) (ibid). Flexible employment practices also include variances in the days and hours of work, part-time work, accumulated working hours (on a timely basis e.g. monthly, yearly), job sharing, temporary employment, contracted working hours and telework (Hogarth, Hasluck and Pierre 2000). We can conclude that the literature fails to provide clear clusters of flexible employment practices and clearly shows that there is a demand for more flexible work. 
Employees in European countries continue to require increased workplace flexibility, although their needs are not always specified as requests for greater work-life balance. This situation is unclear as work-life balance is a recent phenomenon (European Foundation 2003). The European Foundation (EF) describes flexible working and includes profiles of 'atypical work' in its report Flexibility and working conditions: A qualitative and comparative study in seven EU member countries (European Foundation 2000). Classifications of 'atypical work', according to the EF, include non-permanent employment, temporary agency work, part-time employment and self-employment. This study, however, fails to provide data on trends in terms of what 'atypical work' will become. The EF also states there are significant divergences in EU countries in the distribution of what is described as 'atypical work'. These differences included variances in labour legislation, social effects and gender roles (European Foundation 2003).

According to the EF, working conditions in the EU have worsened (European Foundation 2003). These include ergonomic conditions and unfavourable working environments. In the EU it was found by the European Foundation $(2000,2003)$ that although flexible working has been brought to light beginning in the 1980's and has gained momentum since, the growth of non-permanent and part-time work has brought precarious aspects to employment. These aspects include poor health due to stress and physical fatigue due to increased pressure.

It was found in the EF study (2003) that there is an overall increase in non-permanent work. This can be found equally amongst men and women in EU countries (European Foundation 2003). The trend is prevalent in EU countries, albeit large differences in sectors and occupations (ibid). Significant trends in employment flexibility in Europe were found in the same study (ibid) by the EF over a five-year period (1995-2000), with a sample size of 21,500. These include:

- $\quad$ non-permanent employees are either young (less than 25 years) or old (more than 65 years);

- $\quad$ the proportion of those in self-employment increases with the age of workers (ibid).

In can be concluded that according to results from the study done by the European Foundation (2003) there is an increase in employment precariousness due to increased workplace flexibility. Workers expressed, however, greater flexibility in organising work time and gaining a strengthened sense of control (ibid). In the same vein, it is unclear from the literature what types of flexibility are referred to (e.g. temporal flexibility, flexibility based on skill sets, etc.).

\section{Concept of work-life balance}

The term 'work-life balance' was first coined in 1986 (Lockwood 2003). Rosabeth Moss Kanter, in her seminal book Work and family in the United States: A critical review and agenda for research and policy (Kanter 1977), was one of the first to bring the work-life balance issue to light (Lockwood 2003). The main thrust of the work-life balance issue was to support families, notably women with children (ibid). During the 1980s, companies, primarily in the United States (US), began to introduce initiatives to promote well-being in the workplace (ibid).

The work-life balance initiative was significantly fuelled in the academic world through Juliet Schor's influential study The Overworked American (1991). She claims that the number of working hours in the US includes an additional 163 hours per annum. More inherently linked to the work-life balance concept, she posits that there is a trade-off between employee requirements (such as job satisfaction and pay) and employer needs (such as improved productivity and financial returns). Though gender roles in the workplace have evolved due to increased familyrelated benefits of the flexible workplace (Nieto 2003), work-life balance issues appear to be less gender-specific (Lockwood 2003). What exactly does work-life balance mean and how is it interpreted today?

Despite numerous exemplars used to define work-life balance, several key definitions merit comparison:

The meaning of work-life balance has chameleon characteristics. It means different things to different groups, and the meaning often depends on the context of the conversation and the speaker's viewpoint (Lockwood 2003).

...introducing policies and practice which held employees obtain a better balance between work and the rest of their lives (Hogarth, Hasluck and Pierre 2001). 
...to enable men and women to reconcile the demands of work with the needs of home life (Scheibl 1999).

Essentially, work-life balance is about helping employees better managed their work and non-work time. The debate on work-life balance must include employers - encouraging them to understand and implement more effective work-life balance strategies (Wise 2001).

Nevertheless, it is unclear from the above definitions if a universally recognised term to describe work-life balance exists. It is, however, clear that the term work-life balance is derived from divergent issues between workand non-work life.

For the purpose of this study we will therefore refer to work-life balance simply as the way people manage sets of issues linked to their work- versus non-work lives.

\section{Work-life balance initiatives in Europe}

In order to look at the context of work-life balance and working hours in Europe, we will review some significant work-life balance initiatives pertaining to the work week in a sample of European countries. The data reviewed comes from the European Foundation's report Working Time Preferences and work-life balance in the EU: some policy considerations for enhancing the quality of life (2003). Arrangements to enhance work-life balance initiatives in the EU include several measures to allow flexible working hours, including compressing the work week (ibid). The limited number of countries in our review was chosen for purposes of brevity and scope.

The 35 hour work week is one recent example of France's attempt to reduce work hours and positively affect work-life balance (Méda 2004). The Loi Aubry of 1998 and 2000 reduced statutory working hours per week from 39 (voted into law from 40 in 1982) as of 1 January 2000 for companies with more than 20 employees and as of 1 January 2001 for others (European Foundation 2003). The introduction of the 35 hour work week forced employers to negotiate with social partners on a variety of issues such as the annualisation of work-time, part-time work and the organisation of annual and overtime leave (ibid).

The implementation of the 35 hour work week is still experiencing growing pains since it has not yet been unanimously accepted by all sectors of the French economy, notably some labour unions. It was found, however, that the 35 hour work week has had opposing impacts on work-life balance: surveys of employees show that their quality of life had improved but their working pressure had intensified and that hours were more irregular (European Foundation 2003). It was also found that although France enjoys some of the shortest working hours in Europe, studies show that the French feel that they do not have enough time (Méda 2004). Generally, it was found that most people who needed more time are working women with young children and less so for men (ibid).

In Belgium, work-life initiatives have also been focused on the reduction of the work week (European Foundation 2003). The Belgian Minister of Employment and Labour (Laurette Onkelinx) currently advocates legislation for the implementation of a 38 hour work week to be further reduced to 35 hours. Her campaign is called 'More time for oneself. More jobs for all' (ibid). This message is in-line with France's implementation of the 35 hour work week, though Belgium is constrained by a 1996 law which obliges social partners to limit salary costs in order to limit wage costs. This law not only restricts negotiation (ibid), but also limits employment flexibility since salaries for workers cannot be easily counter-balanced with non-monetary benefits.

Denmark introduced a 37 hour work week in 1997 (European Foundation 2003). Denmark's focus on the enhancement of work-life balance vis-à-vis working hours has not been to reduce them, but to render work schedules more adaptable to families with young children (ibid). It was found in one recent study (ibid) that $41 \%$ of Danes surveyed would like to work from home one to two days per week.

In Spain the desire to reduce the work week to 35 hours has been concentrated in jobs in public services and administrations. Though the proposal for the 35 hour work week was rejected in Spain, some regional governments have implemented work-time reduction. In spite of this, only modest steps have been achieved on a national level, including the annualisation of working time in some sectors (ibid). 
Although work-life balance initiatives for the reduction of the work week have been introduced in the countries reviewed, only France has taken legislative measures to significantly reduce the work week by implementing the 35 hour work week and, de facto, force social partners to negotiate and redefine working conditions.

\section{Work-life balance initiatives in Switzerland}

Recent reports indicate that Switzerland is a prime destination for workers due to its quality of life (Amble 2008). In addition, Switzerland enjoys one of the highest levels of education, health and standard of living in the world (Garçon 2008). Swiss government initiatives to maintain work-life balance for employees include the use of flexible working arrangements such as part-time work, flexible hours, annualisation of time and telework (SDC 2009).

The Swiss employment model is atypical in the European context for several reasons. Work contracts are flexible, unemployment benefits are generous and there is a tradition of compromise in work relations (Garçon 2008). Strikes are rare and there appears to be a general consensus that work contributes to the prosperity of the nation (ibid). Moreover, the Swiss voted not to accept a 36 hour working week in 2002 and to maintain an average work week of 41 hours. Swiss workers also have relatively low participation rates in unions (approximately $25 \%$ in 2005) (SDC 2009).

The literature claims that workers in Switzerland appear to be relatively satisfied with their jobs, yet fails to indicate which elements of work-life balance are the most valuable to them. The abundance of studies on working time in Europe carried out by the European Foundation (European Foundation 2003) fail to provide data for Switzerland since it is not an EU member country. Switzerland carries out studies on the effects of work-life balance on workers through consortia such as those of the University of Zurich (2009) and government bodies such as the conference on work-life balance held at the University of Saint Gallen (2007). Despite this, the literature lacks cases which bring to light work-life balance issues for employees in a Swiss hospitality context.

\section{Work-life balance initiatives in the hospitality industry}

The hospitality industry has traditionally been known to have a long-hours culture (Cushing 2004). The literature also indicates that long working hours can lead to burn out for hospitality employees (Buick and Thomas 2001). The literature on work-life balance in the hospitality industry in the United States and the United Kingdom emphasises the use of family friendly practices to attract employees (Doherty 2004). In addition, the literature suggests that there are key issues related to work-life balance to consider in the hospitality industry, mostly related to labour shortage and turnover (Deery and Jago 2008). The literature also suggests that work-life balance issues in hospitality are shaped by employees' desires for increased job satisfaction and employers' desires for increased organisation commitment (ibid). There is, however, a lack of knowledge on work-life balance in the hospitality industry in Swiss-based organisations. Moreover, work-life balance initiatives in the hospitality industry have mainly focused on working hours (Cushing 2004) and fail to provide linkages in other areas that could be applied to our case in the Swiss context. In addition, the literature suggests that work-life balance is a competitive advantage for employers in order to increase loyalty of employees (Joshi, Leichne, Melanson, Pruna, Sager, Story and Williams 2002). This study attempts to fill this gap by providing a case study of work-life balance for employees at a Geneva-based hotel.

\section{Research questions}

The above literature review reveals two key research questions:

1. How does flexibility affect employee perceptions of work-life balance?

2. How do work-life balance issues affect employees in the hospitality industry?

In our study we investigate these questions by focusing on a group of employees at a Geneva-based hotel to extract perceived work-life balance advantages and disadvantages. 


\section{METHODOLOGY}

\section{Theoretical basis for chosen methodology}

This study is based on the assumption that by studying work-life balance within context, we can perceive related implications for employees. According to Yin (1994), case studies such as this one, could contribute to theoretical generalisation, and be further applicable to other, similar cases. Strauss and Corbin (1998) also claim that if concepts are sufficiently developed, they are likely to occur in variant forms of other organisations. These issues can support future hypotheses for replicability and potentially lead to substantive theory.

\section{Data collection}

Data collection for this study is based on self-administered questionnaires, through the head of human resources at a hotel in Geneva. Question content was developed so that key concepts (for data evaluation) were identifiable. Content was based on study research questions. An emphasis was made on evaluating vocabulary and word usage in order to enhance understanding. In addition, questions were reviewed and amended in order to avoid potential bias.

Positively- and negatively-worded questions were used interchangeably in order to mitigate respondents' potential tendency to mechanically answer one end of a scale, as advocated by Sekaran (2000). The length of questions was also kept to less than 20 words, whenever possible. This is also advocated by Sekaran (ibid) in addition to sequencing from the general to the specific (ibid).

The questionnaire was developed on a series of measures based on scales (Sekaran 2000), in this case standardised attitude scales and open-ended questions. Their collective use in this study is particularly useful due to the relatively small number of study participants (30).

Attitude scales are useful since they provide numerical values for behaviour. In our study we used a summated rating scale: a set of attitude items, all of which are considered to be of approximately equal attitude value. The summated rating scale used in questionnaires included a range of replies: 'strongly agree' to 'strongly disagree'. Study participants could respond with degrees of agreement or disagreement. The scores from their replies can then be evaluated to give attitude scores.

60 questionnaires were distributed in electronic format internally March 2009 to managerial level employees by the head of human resources at the hotel. It was decided to focus on these employees since they could guarantee a high reply rate and all spoke fluent English. A reminder email was sent to recipients who did not reply mid April 2009. By the end of April 2009 a total of 30 questionnaires, or 50\%, were received (cf. Table 1 which illustrates questionnaire reply rates).

Table 1: Questionnaire reply rates

\begin{tabular}{lll}
\hline & Frequency & Percent \\
\hline Questionnaires sent & 60 & $50 \%$ \\
Questionnaires received & 30 & $50 \%$ \\
Total & 60 & $100 \%$ \\
\hline
\end{tabular}

\section{Data analysis}

Quantitative data were counted manually from questionnaires and entered into excel tables. Each participant was attributed an identification number in order to guarantee anonymity. Blank excel tables, labelled with question numbers and questionnaire type were prepared for each question. For each Likert scale-based question, formulae were inserted into excel tables to calculate frequency percentages and descriptive statistics. Quantitative data were counted manually from questionnaires and entered into excel tables labelled according to question. Likert scale findings were then evaluated according to skewness, based on mean and mode. 
For qualitative data, separate lines were used to transcribe data, in landscape format, in excel tables, to provide a printed version that would be easy to view. The use of excel tables was useful to copy/paste data and to transform into documents suitable for Nvivo analysis (transformation of excel into .xls documents was necessary for this). The use of tables was also useful to facilitate visual scanning and bundling of text that would provide Meaning Units, or MUs. MUs (Giorgi 1994) represent groups of text, not necessarily full sentences or paragraphs, that give meaning from text. This was a useful method to extrapolate qualitative data and match them for the discussion of research questions. Text was thus broken down into 'chunks' of sentences in open-ended question replies. As a result, MUs could be identified (Giorgi 1985, 1994). They were sorted according to research question theme in order to support Likert scale findings.

\section{DISCUSSION AND CONCLUSION}

\section{Main findings}

The literature claims that there is an increased demand in several European countries for increased work place flexibility (EF 2004), which is also supported by initiatives from the Swiss government for federal employees (SDC 2009). These findings are congruent with those in the sample (cf. Table 2 which illustrates key Likert scale findings in terms of employee perceptions of flexibility of work-related schedules). Nevertheless, there is at least one caveat. Likert scale findings suggest that study participants do not feel they have flexibility in arranging workrelated schedules. Qualitative comments provide deeper insight into this. Typical replies include:

One must sacrifice time as part of work. This is the rhythm of life - a passion (anonymous participant).

I do this job because I love it so I don't want to complain. Life is life and when you want something you have to work hard for it (anonymous participant).

The above statements suggest that participants in the study feel that decreased flexibility is counterbalanced by their emotional commitment to the company. This is congruent with findings from J. Schor (1991) who claims that there is a trade-off, in this sense, between employee requirements and employer needs. This is also congruent with Deer and Jago (2008) who claim that organisation commitment can affect turnover intentions (2008).

Table 2: Likert scale findings in terms of employee perceptions of flexibility of work-related schedules

\begin{tabular}{lll}
\hline & $\begin{array}{c}\text { Question: "I have flexibility in arranging work-related schedules". } \\
\text { Frequency }\end{array}$ & $3 \%$ \\
\hline Not answered & 1 & $30 \%$ \\
Strongly agree & 9 & $55 \%$ \\
Agree & 16 & $9 \%$ \\
Neither agree nor disagree & 3 & $3 \%$ \\
Disagree & 1 & $0 \%$ \\
Strongly disagree & 0 & $100 \%$ \\
Total & 30 & 0 \\
\hline
\end{tabular}

It has become conventional wisdom that work- and non-work responsibilities contribute to work-life balance. Furthermore, the literature has provided streams of studies which focus on the boundaries between workand non-work life (Kanter 1977, Lockwood 2003, Nieto 2003, Schor 1991). Few studies, however, have focused on work-life balance in the hospitality industry in a Swiss context. Findings from the sample suggest that staff surveyed feel that their work lives significantly spill into their personal lives (cf. Table 3 which illustrates key Likert scale findings in terms of employee perceptions in terms of conflict between work and personal responsibilities). This is congruent with the literature in at least two ways. First, findings in the literature suggest that burnout is common (Buick and Thomas 2001). Nevertheless, in the literature work-life balance initiatives in hospitality have focused on working hours, which is in contradiction to findings from the sample (34\% of participants claim to work overtime on a regular basis). 
Table 3: Likert scale findings in terms of employee perceptions in terms of conflict between work and personal responsibilities

\begin{tabular}{lll}
\hline & $\begin{array}{c}\text { Question: "My work spills into my personal life". } \\
\text { Percent }\end{array}$ \\
\hline Not answered & Frequency & $0 \%$ \\
Strongly agree & 0 & $25 \%$ \\
Agree & 7 & $36 \%$ \\
Neither agree nor disagree & 10 & $24 \%$ \\
Disagree & 8 & $12 \%$ \\
Strongly disagree & 4 & $3 \%$ \\
Total & 1 & $100 \%$ \\
\hline
\end{tabular}

Results also suggest that increased flexibility is an advantage to balance work- and non-work life. This is supported by the literature in findings from a series of EU countries by the EF (2004). Nevertheless, participants in our study also claimed that working hours could be relatively flexible and allow free time slots. One participant claimed that although split-shifts provided more complex time management for family reasons, it is considered part of the job. Another key finding suggests that longer working hours are related to an increased difficulty to manage work-related schedules to make time for non-work life. These findings are congruent with those in the branch of the work-life balance literature focusing on hospitality (Cushing 2004, Deery and Jego 2008) which claims that long hours are commonplace.

Disadvantages include the increased sacrifice of private life for work reasons, which is fuelled by the increased difficulty to fit family events and personal schedules into work schedules. This is congruent with the literature which claims that long hours in hospitality can lead to burn-out (Buick and Thomas 2001, Deer and Jago 2008). However, findings from the sample suggest that employees without families perceive moderate levels of work-life balance conflict. Other findings reveal a perception that invasive working hours are due to the difficulty to make short-term (e.g. emergencies) and long-term (e.g. holidays) plans. This is congruent with the literature (ibid), although study participants claim that this is mitigated when they have less family responsibilities. This was especially emphasised by single participants in the study.

Results suggest that decreased social and family life is a disadvantage due to increased difficulty to find free time slots. This is incongruent with Swiss government initiatives (SDC 2009) which claim that a variety of work arrangements (including flexible schedules) contribute to the ability to maintain work-life balance. This is supported by the perception from study participants in our study that increased fatigue and stress are related to the increased difficulty to find time for rest. Study findings which support this include less time for personal events due to fatigue. Again, this is congruent with findings by Cushing (2004) which claims that the hospitality industry is known to have a long-hours culture.

In conclusion, findings indicate that study participants consider work-life balance issues important. This is congruent with the literature (Deery and Jago 2008, Joshi et al. 2002) which claims that work-life balance issues are a competitive advantage for employers. Comments from participants suggest that although many issues are congruent with those found in the literature, this study sheds new light on work-life balance in a Geneva hotel context in at least three ways. First, findings reveal that staff surveyed perceived less work-life balance conflict than suggested by the literature. Second, staff perceptions of work-life balance conflict appear to be mitigated through organisational support (such as flexible schedules). Finally, this study underlines the importance to recognise formal means, such as this study, to gain feedback on work-life balance issues.

\section{Study limitations and future research}

Any strengths of this study are shared with those who provided feedback. All shortcomings are mine alone. This study is limited to one case in the Geneva-based hotel industry. It is unclear if findings can therefore be generalised. Moreover, contextual factors, such as the type of study participants (e.g. English-speaking employees in this case), could also affect this. Finally, there remains a lack of studies on work-life balance issues in the Swiss context as a means of comparison. This study therefore only partially fills, albeit through one lens (employees), the 
gap in this branch of the literature. For future research, it could be useful to investigate work-life balance issues in a similar context from dual perspectives, such as line managers and their employees, to compare and contrast their experiences.

\section{REFERENCES}

1. Amble, B. (2008), "European Talent Heads for Switzerland", available at: http://www.managementissues.com/2008/8/14/research/european-talent-heads-for-Switzerland (accessed 22 March 2009).

2. $\quad$ Buick, I. and Thomas, M. (2001), "Why do middle managers in hotels burn out?", International Journal of Contemporary Hospitality Management, 13 (6), pp. 304-309.

3. Creswell, J. (2003), Research Design, Sage, London.

4. Cushing, K. (2004), “Concerns Raised over UK long-hours culture”, Caterer and Hotelkeeper, 193 (4327, June) p. 14.

5. Deery, M. and Jago, L. (2008), “A framework for work-life balance practices: Addressing the needs of the tourism industry", Toursim and Hospitality Research, Vol. 9, 2, pp. 97-108.

6. Doherty, L (2004), "Work-life balance initiatives: implications for women”, Employee Relations, 26 (4), pp. 433-452.

7. European Foundation for the Improvement of Living and Working Conditions (2000), Flexibility and working conditions: A qualitative and comparative study in seven EU Member States, European Foundation, Dublin.

8. $\quad$ European Foundation for the Improvement of Living and Working Conditions (2003), Working times preferences and work-life balance in the EU: some policy considerations for enhancing the quality of life, European Foundation, Dublin.

9. Garçon, F. (2008), Le Modèle Suisse, Pourquoi ils s'en sortent beaucoup mieux que les autres, Editions Perrin, Paris.

10. Giorgi, A. (1985), "Sketch of a Psychological Phenomenological Method", In: Girogi, A. (Eds.), Phenomenology and Psychological Research, Duquesne University Press, Pittsburgh.

11. Giorgi, A. (1994), “A Phenomenological Perspective on Certain Qualitative Research Methods", Journal of Phenomenological Research, Vol. 25, No. 2, pp. 190-220.

12. Hogarth, T., Hasluck, C. and Pierre, G. (2000), "Work-Life Balance 2000, Results from the Baseline Study", Institute for Employment Research, report RR249, University of Warwick, Warwick.

13. Joshi, S., Leichne, J., Melanson, K., Pruna, C., Sager, N., Story, C.J. and Williams, K. (2002), "Work-Life Balance. A Case of Social Responsibility of Competitive Advantage?", Human Resources Department, Georgia Institute of technology, available at: http://www.worklifebalance.com/assets/pdfs/casestudy.pdf (accessed 25 March 2009).

14. Kanter, R. (1977), Work and family in the United States: A critical review and agenda for research and policy, Russell Sage Foundation, New York.

15. Lockwood, N. (2003), "Work-Life Balance, Challenges and Solutions", Society for Human Resource Management (SHRM) Research Department, SHRM, Alexandria, VA.

16. Nieto, M. (2003), "The development of life work balance initiatives designed for managerial workers", Business Ethics, July, Vol. 12, issue 3.

17. Scheibl, F. (1999), "Measure and communicate the benefits of work-life policies more effectively?", ESRC Centre for Business Research, University of Cambridge, working paper No. 135, University of Cambridge.

18. Schor, J. (1991), The Overworked American, New York, Basic Books.

19. Sekaran, U. (2000), Research Methods for Business, John Wiley and Sons, New York.

20. Strauss, A. and Corbin, J. (1998), Basics of qualitative research: Techniques and procedures for developing grounded theory, Sage, London.

21. Swiss Agency for Development and Co-operation (SDC) (2009), http://www.sdc.admin.ch (accessed 20 March 2009).

22. University of Saint Gallen (2007), "Work-life balance as a strength for organisations and workers", National convention for the promotion of health at work, held 29 March 2007, Saint Gallen.

23. University of Zurich (2009), "Work-life imbalance and health disorders in Switzerland", work in progress available at: http://www.research-projects.uzh.ch/p9404.htm (accessed 25 March 2009).

24. Yin, R. (1994), Case Study Research: Design and Methods, Sage, London. 